\title{
Characteristics and clinical features of children presenting with acute myocarditis at a tertiary care hospital.
}

1. FCPS (Pediatric Medicine)

Assistant Professor Pediatrics Fatima Jinnah Medical University/ Sir Gangaram Hospital, Lahore.

2. FCPS (Pediatric Medicine)

Assistant Professor Pediatric Medicine

Shalamar Medical and Dental College Lahore.

3. FCPS (Pediatric Medicine) Assistant Professor Pediatric Medicine

Pir Abdul Qadir Shah Jillani Institute of Medical Sciences, Gambat.

4. FCPS (Pediatric Medicine) Senior Registrar Pediatrics Sahara Medical College Narowal.

5. FCPS (Pediatric Medicine) Fellow Pediatric Cardiology NICVD, Karachi.

6. FCPS (Pediatric Medicine) Associate Professor Pediatrics Sahara Medical College Narowal.

Correspondence Address:

Dr. Farhan Zahoor

Assistant Professor Pediatrics

Fatima Jinnah Medical University/

Sir Gangaram Hospital, Lahore.

drf.zahoor@gmail.com

Article received on:

24/03/2021

Accepted for publication:

28/05/2021

\section{INTRODUCTION}

Myocarditis is known be an inflammatory disease of the myocardium. ${ }^{1}$ Exact incidence of myocarditis is not known but it is roughly estimated to account for $1 / 100000$ in pediatric population. ${ }^{2}$ Myocarditis can be due to infections caused by viruses, bacteria or parasites or it could be because of non-infectious causes like drugs (e.g., anthracyclines). ${ }^{3}$ Viruses are considered to be the most frequent reason behind myocarditis and, in the past, coxackie $B$ virus has been the commonest cardiotoxic virus. In the recent times, shifts have been observed in epidemiology of myocarditis and parvo virus B19 is thought to be the most frequent virus behind myocarditis. ${ }^{4}$ As myocarditis due to bacteria has been seen in $0.2 \%-1.5 \%$ cases but bacterial causes should be suspected especially in cases where ventricular failure and sepsis is found. ${ }^{5}$
The exact pathophysiology of myocarditis is not fully known but three phases as are generally described as first being the entry of the causative agent, second is the autoimmune response and third phase is the chronic phase that can lead to remodeling of the myocardial muscle and dilated cardiomyopathy. ${ }^{6,7}$ Cases of myocarditis can present varying from mild-subclinical course to acute heart failure. Among children without any past history of cardiac failure, acute myocarditis is considered to be the commonest clinical presentation of acute cardiac failure. ${ }^{8}$ Tachypnea, tachycardia and grunting are some of the commonest general presentations. ${ }^{9}$ Some cases present with nausea and vomiting which makes the diagnosis confusing and situation can be worse if these cases are treated with intravenous fluids suspecting acute gastritis which can further lead to congestive heart failure. 
Chest radiograph, electrocardiogram, cardiac enzymes, cardiovascular magnetic resonance (CMR) as well as viral serology are some of the most important tools for diagnosing myocarditis but endomyocardial biopsy is considered to be the gold standard for the diagnosis of myocarditis. ${ }^{10}$ In Pakistan, not much work is seen regarding clinical profile and characteristics of acute myocarditis so current study was done to find out characteristics and clinical features of children presenting with acute myocarditis at a tertiary care hospital.

\section{MATERIAL \& METHODS}

This observational study was done at The Department of Pediatrics, Sughra Shafi Medical Complex, Sahara Medical College, Narowal, Pakistan from February 2020 to February 2021. Approval from institutional ethical committee was acquired for this study. Written consent was sought from parents/guardians of all study participants.

A total of 71 children aged 1 month to 15 years admitted with acute myocarditis were enrolled. Acute myocarditis was labeled as short history of illness in otherwise healthy child, echocardiography showing left ventricular dysfunctioning, cardiac biomarkers showing cardiac damage as well as electrocardiography showing acute myocarditis. ${ }^{11}$ Children having congenital heart defects or those with family history of cardiomyopathy were excluded. Children having radiological evidence of lung disorders or those having malaria, typhoid fever, dengue fever or COVID-19 were also excluded.

A special proforma was made for recording all study information. SPSS version 26.0 was used for data entry and analysis. Quantitative variable like age was represented as mean and standard deviation whereas qualitative variables like gender, area of residence and clinical features were shown as frequency and percentages.

\section{RESULTS}

Out of a total of 71 children, there were 38 $(53.5 \%)$ were male. Median age was recorded to be 16.6 months. Majority of the cases, 42
(59.2\%) belonged to rural areas of residence. As per institutional criteria, 43 (60.6\%) children were admitted in intensive care unit while remaining $28(39.4 \%)$ were admitted in the ward. Table-l is showing characteristics of the children with acute myocarditis.

\begin{tabular}{|l|c|c|}
\hline \multicolumn{2}{|c|}{ Characteristics } & Number (\%) \\
\hline \multirow{2}{*}{ Gender } & Male & $38(53.5 \%)$ \\
\hline \multirow{2}{*}{$\begin{array}{l}\text { Area of } \\
\text { Residence }\end{array}$} & Female & $33(46.5 \%)$ \\
\hline $\begin{array}{l}\text { Malnutrition } \\
\text { (<-3SD) }\end{array}$ & Urban & $29(40.8 \%)$ \\
\hline Admission & Yes & $42(59.2 \%)$ \\
\hline \multicolumn{2}{|c|}{ Table-I. Characteristics of children with acute } \\
\cline { 2 - 3 } & No & $28(39.4 \%)$ \\
\hline
\end{tabular}

Tachycardia was the commonest clinical feature noted in $65(91.5 \%)$ children, irritability was seen in $50(70.4 \%)$, tachypnea in $48(67.6 \%)$ while poor feeding was noted $44(62.0 \%)$ children. Table-II is showing frequency of most common clinical features noted in the present study. Hepatomegaly was noted in 39 (54.9\%) children. Hypotension was recorded in 35 (49.3\%) children.

\begin{tabular}{|l|c|}
\hline \multicolumn{1}{|c|}{ Clinical Features } & Number (\%) \\
\hline Tachycardia & $65(91.5 \%)$ \\
\hline Irritability & $50(70.4 \%)$ \\
\hline Tachypnea & $48(67.6 \%)$ \\
\hline Anorexia/Poor Feeding & $44(62.0 \%)$ \\
\hline Lethargy & $43(60.6 \%)$ \\
\hline Fever & $42(59.1 \%)$ \\
\hline Cough & $41(57.7 \%)$ \\
\hline Chest Basal Crepitations & $40(56.3 \%)$ \\
\hline \multicolumn{2}{|c|}{ Table-II. Frequency of most common clinical features } \\
in children with acute myocarditis. (n=71)
\end{tabular}

\section{DISCUSSION}

As acute myocarditis is an important morbidity and mortality in the paediatric age groups, but not much is known in Pakistan about its presentation and clinical features. As diagnosis is commonly based on high index of suspicion while acute myocarditis generally present with 
non-specific symptoms. As myocardial biopsy is considered to be the gold standard regarding definitive diagnosis of myocarditis but resource limited countries like Pakistan do not always have the luxury of myocardial biopsy at our disposal. ${ }^{10}$ So, in our population, it is very important to find out most common modes of clinical features in children presenting with acute myocarditis.

In the present study, majority of the children (53.5\%) were male. A local study done by Haider $\mathrm{N}$ et al evaluating children with acute myocarditis also revealed that $55 \%$ of their patients were male. ${ }^{11}$ Effects of cardioprotective hormones among females could be a reason behind this male predominance in children having acute myocarditis. ${ }^{12}$

We found that tachycardia was the commonest clinical feature noted in 65 (91.5\%) children, irritability was seen in 50 (70.4\%), tachypnea in 48 (67.6\%) while poor feeding was noted 44 (62.0\%) children. Hepatomegaly was noted in 39 (54.9\%) children. Hypotension was recorded in 35 (49.3\%) children. Wide spectrum of clinical features among children presenting with acute myocarditis have been reported in the literature. Durrani $Y$ et al from USA analyzing clinical characteristics of children with acute myocarditis found shortness of breath, vomiting or anorexia to be the most common clinical characteristics seen in 69\%, 48\% and $40 \%$ children respectively. ${ }^{13}$ Study done Hsiao HJ from Taiwan found gastrointestinal symptoms to form most frequent chunk of clinical presentation which is somewhat different to what we noted in the present study. ${ }^{14}$ Although Hsiao $\mathrm{HJ}$ et al found gastrointestinal symptoms to form most common clinical presentation of acute myocarditis but they noted tachycardia to be present in $63 \%$ of cases which is again highlighting that tachycardia is very common clinical presentation among children with acute myocarditis.

Local data showed tachycardia (90.3\%), poor capillary refill (87.1\%) and irritability (72.6\%) to be the most common clinical features noted among children with acute myocarditis and these findings were quite similar to what was noted in the present study. ${ }^{11}$ Data from India showed dyspnea (83.7\%), tachycardia (81.4\%) and chest pain $(39.5 \%)$ to be most common clinical features among children with acute myocarditis. ${ }^{15}$ Studies involving comparatively older children are seen to present predominant number of children with gastrointestinal / abdominal symptoms which could be due to the reason that older children can verbalize and tell their complaints but relatively young children as we had median age as 16.6 months in the present study are unable to describe their chief complaints. ${ }^{15}$ It is also evident from the past studies that that children presenting with acute myocarditis frequently present with gastrointestinal symptoms but these can be confused with gastroenteritis and might make the diagnosis difficult. ${ }^{16-18}$

Although, we did not evaluate etiological aspects of acute myocarditis in the present study but some researchers have pointed out that different types of etiological agents can probably induce different kinds of clinical features as Mahrholdt $\mathrm{KU}$ showed that children having parvo virus B19 were commonly presenting with complaints of abdominal pain. ${ }^{19}$

Our study had some limitations as well. We were unable to evaluate etiological agents responsible for acute myocarditis in our set of patients. Being an observational study where data was recorded at the time of admission, we could not track laboratory and investigational aspects in the presents study. No data about the treatment or outcome in our children was analyzed for the purpose of this study.

\section{CONCLUSION}

Male predominance was seen among children presenting with acute myocarditis. Tachycardia, irritability, tachypnea and poor feeding were the commonest clinical features observed.

\section{Copyright $@ 28$ May, 2021.}

\section{REFERENCES}

1. Bejiqi R, Retkoceri R, Maloku A, Mustafa A, Bejiqi H, Bejiqi $R$. The diagnostic and clinical approach to pediatric myocarditis: A review of the current literature. Open Access Maced J Med Sci. 2019; 7(1):162-173. 
2. Levine MC, Klugman D, Teach SJ. Update on myocarditis in children. Curr Opin Pediatr. 2010; 22(3)278-83.

3. Sparrow PJ, Merchant N, Provost YL, Doyle DJ, Nguyen $E T$, Paul NS. CT and MR imaging findings in patients with acquired heart disease at risk for sudden cardiac death. Radiographics 2009; 29: 805-23.

4. Spartalis M, Tzatzaki E, Spartalis E, Damaskos C, Mavrogeni S, Voudris V. Parvovirus B19 myocarditis of fulminant evolution. Cardiol Res. 2017; 8(4):172-5.

5. Villablanca P, Mohananey D, Meier G, Yap JE, Chouksey $S$, Abegunde AT. Salmonella Berta myocarditis: Case report and systematic review of non-typhoid Salmonella myocarditis. World J Cardiol. 2015; 7(12):931-937.

6. Al-Akchar M, Kiel J. Acute myocarditis. [Updated 2020 May 21]. In: StatPearls [Internet]. Treasure Island (FL): StatPearls Publishing; 2021 Jan-. Available from: https:// www.ncbi.nlm.nih.gov/books/NBK441847/.

7. Kindermann I, Barth C, Mahfoud F, Ukena C, Lenski M, Yilmaz A, et al. Update on myocarditis. J Am Coll Cardiol. 2012; 59(9):779-92.

8. Freedman SB, Haladyn JK, Floh A, Kirsh JA, Taylor G, Thull-Freedman J. Pediatric myocarditis: Emergency department clinical findings and diagnostic evaluation. Pediatrics. 2007; 120(6):1278-85.

9. Blauwet LA, Cooper LT. Myocarditis. Prog Cardiovasc Dis. 2010; 52(4):274-88.

10. Dominguez F, Kühl U, Pieske B, Garcia-Pavia $P$, Tschöpe C. Update on myocarditis and inflammatory cardiomyopathy: Reemergence of endomyocardial biopsy. Rev Esp Cardiol (Engl Ed). 2016; 69(2):178-87.
11. Haider N, Shaikh AS, Wazir R, Atiq M. Clinicodemographic features and outcome of acute myocarditis in children admitted at tertiary care hospital. Int J Cardiol. 2016 Oct 15; 221:42-5.

12. Schwartz J, Sartini D, Huber S. Myocarditis susceptibility in female mice depends upon ovarian cycle phase at infection. Virology. 2004; 330(1):16-23.

13. Durani Y, Egan M, Baffa J, Selbst SM, Nager AL. Pediatric myocarditis: Presenting clinical characteristics. Am J Emerg Med. 2009; 27(8):942-7.

14. Hsiao HJ, Hsia SH, Wu CT, Lin JJ, Chung HS, Hwang MS. Clinical presentation of pediatric myocarditis in Taiwan, Pediatr Neonatol. 2011; 52(3):135-9.

15. Abrar S, Ansari MJ, Mittal M, Mehta A, Sharma B, Srivastava SK, et al. Myocarditis in children presenting with acute febrile illness. Int J Pediatr Res 2016; $3(3): 185-92$.

16. Chang YJ, Chao HC, Hsia SH, Yan DC. Myocarditis presenting as gastritis in children. Pediatr Emerg Care. 2006; 22(6):439-440.

17. Bohn $D$, Benson $L$. Diagnosis and management of pediatric myocarditis. Paediatr Drugs. 2002; 4(3):17181.

18. Levi $\mathrm{D}$, Alejos J. Diagnosis and treatment of pediatric viral myocarditis. Curr Opin Cardiol. 2001; 16(2):7783.

19. Mahrholdt H, Wagner A, Deluigi CC, Kispert E, Hager $S$, Meinhardt $G$, et al. Presentation, patterns of myocardial damage, and clinical course of viral myocarditis. Circulation. 2006; 114(15):1581-90.

\begin{tabular}{|c|l|l|l|}
\hline \multicolumn{3}{|c|}{ AUTHORSHIP AND CONTRIBUTION DECLARATION } \\
\hline No. & \multicolumn{1}{|c|}{ Author(s) Full Name } & \multicolumn{1}{|c|}{ Contribution to the paper } & Author(s) Signature \\
\hline 1 & Farhan Zahoor & Introduction, Proof reading. \\
2 & Bushra Madni & $\begin{array}{l}\text { Literature review, } \\
\text { Methodology. } \\
\text { Data analysis, Discussion. }\end{array}$ \\
\hline 3 & Muhammad Imran & $\begin{array}{l}\text { Literature review, Data } \\
\text { collection. }\end{array}$ \\
\hline 5 & Muhammad Naveed & Fafting, references. \\
6 & Khurram Shahnawaz & $\begin{array}{l}\text { Data Collection, Final } \\
\text { approval. }\end{array}$ \\
\hline
\end{tabular}

